\title{
Luminescence and energy transfer in $\mathrm{La}_{2} \mathrm{O}_{3}-\mathrm{Nb}_{2} \mathrm{O}_{5}-\mathrm{B}_{2} \mathrm{O}_{3}: \mathrm{M}^{3+}(\mathrm{M}=\mathrm{Bi}, \mathrm{Eu}, \mathrm{Dy})$ glasses
}

\author{
Wallace D. Fragoso ${ }^{a}$, Celso de Mello Donegá ${ }^{\mathrm{b}}$, Ricardo L. Longo ${ }^{\mathrm{a}, *}$ \\ ${ }^{a}$ Departamento de Química Fundamental-Universidade Federal de Pernambuco 50740-540, Recife, PE, Brazil \\ ${ }^{\mathrm{b}}$ Debye Institute, Department of Physics and Chemistry of Condensed Matter, Utrecht University, PO Box 80000, 3508 TA Utrecht, \\ The Netherlands
}

Received 26 February 2003; received in revised form 2 June 2003; accepted 2 June 2003

\begin{abstract}
The luminescence and energy transfer processes in $\mathrm{La}_{2} \mathrm{O}_{3}-\mathrm{Nb}_{2} \mathrm{O}_{5}-\mathrm{B}_{2} \mathrm{O}_{3}: \mathrm{M}^{3+}(\mathrm{M}=\mathrm{Bi}$, Eu, Dy) glasses were investigated using luminescence spectroscopy (excitation and emission, down to $4.2 \mathrm{~K}$ ) and decay time measurements at room temperature. The observation of niobate luminescence implies a considerable degree of short- and intermediaterange order in these glasses. Energy transfer from the niobate groups to the lanthanide ions was observed for $\mathrm{Eu}^{3+}$, but not for $\mathrm{Dy}^{3+}$, suggesting that the energy transfer process occurs to the charge-transfer state of the $\mathrm{Eu}^{3+}$ ion, rather than to its f-levels. Inter-Eu ${ }^{3+}$ energy transfer was negligible in the concentration range investigated (up to $3 \mathrm{~mol} \%$ ). In contrast, cross-relaxation processes between $\mathrm{Dy}^{3+}$ ions were active at concentrations as low as $0.5 \mathrm{~mol} \%$. In the $\mathrm{Bi}^{3+}$ doped glasses the energy transfer was observed from the $\mathrm{Bi}^{3+}$ excited levels to the oxygen deficient niobate groups. (C) 2003 Elsevier B.V. All rights reserved.
\end{abstract}

PACS: 78.55.-m; 81.05.Kf; 78.66.Jg; 82.20.Rp

Keywords: Glasses; Niobate luminescence; Lanthanide luminescence; Energy transfer; Nb; La

\section{Introduction}

Niobium containing glasses have several interesting properties, such as large non-linear optical susceptibilities [1-3]. Nevertheless, the structural role of the $\mathrm{Nb}(\mathrm{V})$ cation is still not fully understood. Recently, we have developed new glasses of composition $19 \mathrm{La}_{2} \mathrm{O}_{3-x} \mathrm{M}_{2} \mathrm{O}_{5}-(81-x) \mathrm{B}_{2} \mathrm{O}_{3}$ $(\mathrm{M}=\mathrm{Nb}$ or Ta; $x=0-20)$ [4]. These glasses have showed high chemical resistance, surface hardness

\footnotetext{
*Corresponding author. Tel.: + 55-81-3271-8440; fax: + 5581-3271-8442.

E-mail address: longo@ufpe.br (R.L. Longo).
}

and refractive indices (up to 1.935 for $x=20$ ), excellent transparency in the visible-IR region and intense UV absorption [4]. Their most striking property, however, is the occurrence of niobate and tantalate luminescence upon UV excitation [4], and as far we know, this is still the first and only observation of niobate and tantalate luminescence in glasses. The vibrational, luminescence, absorption and thermal analytical data are consistent with each other, and indicate that the $\mathrm{Nb}(\mathrm{V})$ and $\mathrm{Ta}(\mathrm{V})$ ions are incorporated into the glass network as $\mathrm{MO}_{6}$ octahedra, condensing into subnetworks as the $\mathrm{M}(\mathrm{V})$ concentration increases [4]. 
In this work, we have investigated the possibility of energy transfer between the niobate groups and optically active ions, namely, $\mathrm{Bi}^{3+}, \mathrm{Dy}^{3+}$, and $\mathrm{Eu}^{3+}$. The lanthanide ions $\mathrm{Dy}^{3+}\left(4 \mathrm{f}^{9}\right)$ and $\mathrm{Eu}^{3+}$ $\left(4 \mathrm{f}^{6}\right)$ were chosen because both present efficient luminescence in the visible region and have similar ionic radius, but differ with respect to the excited states resonant with the niobate states. For instance, the $\mathrm{Dy}^{3+}$ ion has only $4 \mathrm{f}$ states, whereas the $\mathrm{Eu}^{3+}$ ion has charge-transfer states in addition to the $4 \mathrm{f}$ states [5]. The $\mathrm{Bi}^{3+}$ ion was chosen for it's closed-shell $6 \mathrm{~s}^{2}$ configuration, which is known to strongly influence the luminescence of $\mathrm{d}^{0}$-complexes, such as the niobate group [5]. Furthermore, the effects of the composition on the niobate luminescence were investigated in order to yield quantitative information on the energy transfer processes.

\section{Experimental}

Glasses with the following designation and composition (i) $[x \mathrm{BLANB} y: z \mathrm{Ln}]:(x-z) \mathrm{La}_{2} \mathrm{O}_{3}-$ $y \mathrm{Nb}_{2} \mathrm{O}_{5}-(100-x-y) \mathrm{B}_{2} \mathrm{O}_{3}: z \operatorname{Ln} \quad(x=19$ or 25 ; $y=1-20 ; \quad z=0-5 ; \quad \mathrm{Ln}=\mathrm{Eu}^{3+}$ or $\left.\mathrm{Dy}^{3+}\right)$; (ii) [BLANB $w$ : $\mathrm{Bi}$ ]: $24.5 \mathrm{La}_{2} \mathrm{O}_{3}-w \mathrm{Nb}_{2} \mathrm{O}_{5}-(75-w) \mathrm{B}_{2} \mathrm{O}_{3}$ : $0.5 \mathrm{Bi}_{2} \mathrm{O}_{3}(w=10-20)$; (iii) [BLA]: $(20-a) \mathrm{La}_{2} \mathrm{O}_{3}-$ $80 \mathrm{~B}_{2} \mathrm{O}_{3}: a \mathrm{Ln}$; and (iv) [BLACN]: $4 \mathrm{CaO}-2 \mathrm{Na}_{2} \mathrm{O}-$ $(19-a) \mathrm{La}_{2} \mathrm{O}_{3}-75 \mathrm{~B}_{2} \mathrm{O}_{3}: a \mathrm{Ln} \quad(a=0-5) \quad$ were prepared from $\mathrm{La}_{2} \mathrm{O}_{3}$ (Alfa, 99.999\%), $\mathrm{Ln}_{2} \mathrm{O}_{3}$ (Aldrich, 99.99\%), $\mathrm{Bi}_{2} \mathrm{O}_{3}$ (Riedel, 99.99\%), $\mathrm{B}_{2} \mathrm{O}_{3}$ (Alfa, 99.999\%) or $\mathrm{H}_{3} \mathrm{BO}_{3}$ (Merck Suprapur), $\mathrm{CaCO}_{3}$ (Alfa, 99.95\%), $\mathrm{Na}_{2} \mathrm{CO}_{3}$ (Alfa, 99.95\%) and $\mathrm{Nb}_{2} \mathrm{O}_{5}$ (Alfa, 99.9985\%) by melting $5 \mathrm{~g}$ batches in uncovered $\mathrm{Pt}$ crucibles at $1200^{\circ} \mathrm{C}$ for $1 \mathrm{~h}$, and subsequently quenching by pouring onto $\mathrm{Pt}$ plates at room temperature. An excess of $12 \mathrm{wt} \%$ of $\mathrm{B}_{2} \mathrm{O}_{3}$ was added to compensate for evaporation losses. In this way the glasses are within $\pm 1 \%$ of the nominal composition.

The luminescence spectra were obtained by using a SPEX DM3000F Spectrofluorometer with double-grating $0.22 \mathrm{~m}$ SPEX 1680 monochromators and a $450 \mathrm{~W}$ Xe Lamp. This setup was equipped with an Oxford LF205 liquid Helium flow cryostat. The spectra were corrected for the instrumental response. Excited state decay-time measurements were performed at $298 \mathrm{~K}$ using the third harmonic of a Nd-YAG laser $(10 \mathrm{~Hz})$ as the excitation source. The emission was detected with a modified 1P28 photomultiplier tube, after dispersion through a $0.25 \mathrm{~m}$ monochromator. The signal was then analyzed on a boxcar. The temporal resolution of the overall system is ca. $50 \mathrm{~ns}$.

\section{Results and discussion}

The luminescence of 19BLANB glasses have already been reported [4] and consist of broad band emission upon UV excitation. The emission and excitation bands shifted to longer wavelengths with increasing $\mathrm{Nb}(\mathrm{V})$ concentration, for instance, the maxima of the emission $\left(\lambda_{\mathrm{em}(\max )}\right)$ and excitation $\left(\lambda_{\operatorname{exc}(\max )}\right)$ were 490 and $280 \mathrm{~nm}$, respectively, for $1 \mathrm{~mol} \% \quad \mathrm{Nb}_{2} \mathrm{O}_{5}$, and 570 and $340 \mathrm{~nm}$ for $20 \mathrm{~mol} \% \quad \mathrm{Nb}_{2} \mathrm{O}_{5}$ [4]. Furthermore, the energy difference between the emission and excitation maxima, the so-called Stokes shift $\left(\Delta_{\mathrm{ST}}\right)$, decreased from 15,300 to $11,800 \mathrm{~cm}^{-1}$ when the $\mathrm{Nb}(\mathrm{V})$ concentration increased from 1 to $20 \mathrm{~mol} \%$. The emission intensity decreased by ca. ten times from when the $\mathrm{Nb}(\mathrm{V})$ concentration increased from 1 to $20 \mathrm{~mol} \% \mathrm{Nb}_{2} \mathrm{O}_{5}$. Excitation at longer wavelengths resulted in a shift of the emission band to lower energies. This shift was more pronounced for higher concentrations. The luminescence intensity decreased 10-100 times when the temperature increased from 4.2 to $300 \mathrm{~K}$ [4].

The luminescence of 25BLANB glasses was very similar to that of 19BLANB glasses [4] in all aspects except for the excitation bands. As a representative example, Fig. 1 shows the excitation and emission spectra of the 25BLANB10 and 19BLANB10 samples at $4.2 \mathrm{~K}$. Although the emission maximum occurred at about the same position (viz. $510 \mathrm{~nm}$ ), the excitation maximum of 25BLANB10 is shifted to much shorter wavelengths $(265 \mathrm{~nm})$ compared to 19BLANB10, and thus leading to a large $\Delta_{\mathrm{ST}}\left(18,000 \mathrm{~cm}^{-1}\right)$. Another difference is the presence in the emission band for 25BLANB10 of a shoulder at $570 \mathrm{~nm}$, whose intensity increases upon excitation at longer wavelengths. 
The niobate luminescence has been extensively investigated in crystalline materials [5-9], and is strongly dependent upon the crystal structure. The most efficient luminescence occurs in niobyl groups [7], i.e., an $\mathrm{Nb}-\mathrm{O}$ group with a short bond distance, approximately $0.17 \mathrm{~nm}$. Structurally isolated $\mathrm{NbO}_{6}$ octahedra, such as in ordered perovskites and in $\mathrm{MgNb}_{2}\left(\mathrm{P}_{2} \mathrm{O}_{7}\right)_{3}$, are not efficient luminescent centers [10], whereas isolated distorted niobate groups, such as in $\mathrm{LaNbO}_{4}$, where the $\mathrm{Nb}(\mathrm{V})$ has a $4+2$ coordination, provide very efficient centers [6]. Edge- or face-shared $\mathrm{NbO}_{6}$ octahedral groups show efficient luminescence with a large $\Delta_{\mathrm{ST}}$, while corner-sharing of $\mathrm{NbO}_{6}$ groups leads to shift of the optical absorption to

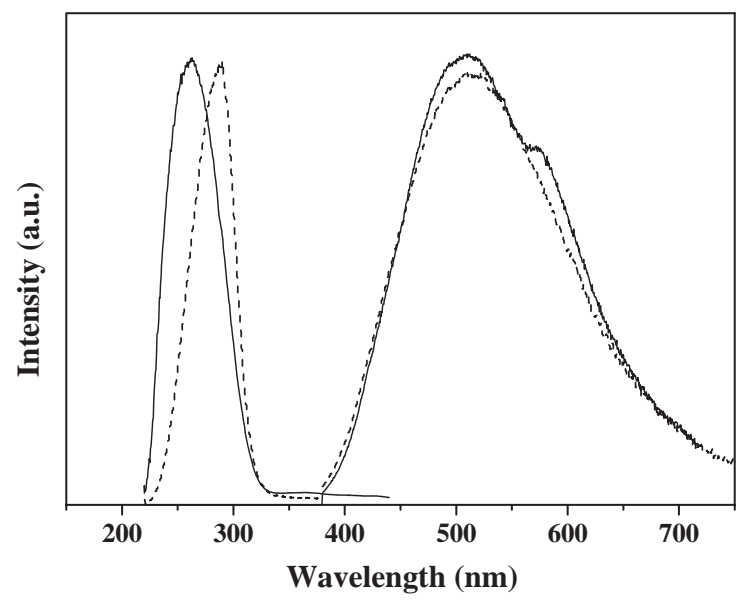

Fig. 1. Emission $\left(\lambda_{\mathrm{exc}}=260 \mathrm{~nm}\right)$ and excitation $\left(\lambda_{\mathrm{em}}=500 \mathrm{~nm}\right)$ spectra of $25 \mathrm{La}_{2} \mathrm{O}_{3}-10 \mathrm{Nb}_{2} \mathrm{O}_{5}-65 \mathrm{~B}_{2} \mathrm{O}_{3}$ (solid line) and $19 \mathrm{La}_{2} \mathrm{O}_{3}-10 \mathrm{Nb}_{2} \mathrm{O}_{5}-71 \mathrm{~B}_{2} \mathrm{O}_{3}$ (dashed line) glasses at $4.2 \mathrm{~K}$. The intensities have been normalized. lower energies, exciton delocalization, smaller $\Delta_{\mathrm{ST}}$, lower quenching temperatures, energy migration and consequently luminescence quenching [6]. The closer the $\mathrm{Nb}-\mathrm{O}-\mathrm{Nb}$ angles are to $180^{\circ}$ the more pronounced the effects of the $\mathrm{NbO}_{6}$ condensation become [6]. Furthermore, cation disorder, such as in $\mathrm{ScNbO}_{4}$ and $\mathrm{MgNb}_{2} \mathrm{O}_{6}$, drastically decreases the luminescence quantum yields and increases the concentration of extrinsic niobate groups, i.e., groups with oxygen deficiency or excess positive charge [6]. These extrinsic groups have been observed in several niobates and present emission and excitation spectra at much longer wavelengths than the intrinsic groups. Some selected spectroscopic properties and their dependence upon the structure are presented in Table 1.

The observation of niobate luminescence thus implies a considerable degree of short- and intermediate-range order in BLANB glasses. Considering the absorption and luminescence spectra [4], and the literature data for crystalline niobates [9] presented in Table 1, it is suggested that at $1 \mathrm{~mol} \% \quad \mathrm{Nb}_{2} \mathrm{O}_{5}$ the $\mathrm{NbO}_{6}$ groups might be condensed into single chains of corner-sharing octahedra with uneven $\mathrm{Nb}-\mathrm{O}$ bond lengths $(0.177$ vs. $0.210 \mathrm{~nm}$ ) leading to approximately isolated $\mathrm{NbO}_{5}$ units [9]. As the $\mathrm{Nb}(\mathrm{V})$ concentration increases these single chains and/or the $\mathrm{NbO}_{5}$ units can condensed into double chains of cornersharing octahedra $\mathrm{NbO}_{6}$ connected in pairs by edge-sharing [9]. This increase in the chains causes a shift of the absorption to lower energies and an increase in energy migration, consistent with the observed values for the emission and excitation wavelengths for the 19BLAN1, 19BLAN10 and

Table 1

Spectroscopic and structural properties of niobate crystals and glasses

\begin{tabular}{|c|c|c|c|c|}
\hline Structure & $\lambda_{\mathrm{abs}(\max )}$ & $\lambda_{\mathrm{em}(\max )}$ & $\lambda_{\operatorname{exc}(\max )}$ & $\Delta_{\mathrm{ST}}$ \\
\hline $\begin{array}{l}\alpha-\mathrm{LaNb}_{3} \mathrm{O}_{9} \text {-double chains of corner-sharing octahedra } \mathrm{NbO}_{6} \text { connected } \\
\text { in pairs by edge-sharing with } \mathrm{Nb}-\mathrm{O}-\mathrm{Nb}=130-150^{\circ}[9] .\end{array}$ & 320 & 535 & 310 & 14,000 \\
\hline $\begin{array}{l}\alpha-\mathrm{NbPO}_{5} \text {-corner-sharing octahedra } \mathrm{NbO}_{6} \text { with } \mathrm{Nb}-\mathrm{O}=0.177 \mathrm{~nm} \text { (niobyl) } \\
\text { and } \mathrm{O}-\mathrm{Nb}=0.210 \mathrm{~nm} \text { leading to approximately isolated } \mathrm{NbO}_{5}[9] .\end{array}$ & - & 490 & 260 & 18,000 \\
\hline 19BLANB1 [4] & 282 & 490 & 280 & 15,300 \\
\hline 19BLANB10 [4] & - & 510 & 290 & 14,800 \\
\hline 19BLANB20 [4] & 330 & 570 & 340 & 11,800 \\
\hline 25BLANB10 [this work] & - & 510 & 265 & 18,100 \\
\hline
\end{tabular}

Maxima absorption, $\lambda_{\mathrm{abs}(\max )}$, emission, $\lambda_{\mathrm{em}(\max )}$, and excitation, $\lambda_{\mathrm{exc}(\max )}$, wavelengths $(\mathrm{nm})$ and Stokes shift, $\Delta_{\mathrm{ST}}\left(\mathrm{cm}^{-1}\right)$. 
19BLAN20 samples (Table 1). The luminescence can be attributed to the trapping of the migrating energy by some $\mathrm{NbO}_{6}$ groups within the niobate subnetwork, although most of the groups will decay non-radiatively. The emission at longer wavelengths can be ascribed to extrinsic groups [6] (niobate groups lacking oxygen or at sites surrounded by borate groups). Due to the glass long-range disorder there will be many chain segments and extrinsic groups with slightly different geometries, giving rise to a dependence of the emission on the excitation wavelengths. As far as the luminescence is concerned, the increase in the $\mathrm{La}^{3+}$ concentration seems to partially disrupt the double chains into single corner-sharing chains, giving rise to some niobyl groups and $\mathrm{NbO}_{6}$ groups with off-center $\mathrm{Nb}(\mathrm{V})$ ions, which is partially consistent with the luminescence results for the 19BLAN10 and 25BLAN10 samples (Table 1).

The $\mathrm{Ln}^{3+}$ doped BLANB samples presented the characteristic $\mathrm{Ln}^{3+}$ luminescence, namely, the ${ }^{5} \mathrm{D}_{0} \rightarrow{ }^{7} \mathrm{~F}_{\mathrm{J}}$ transitions, $J=0-14$ for $\mathrm{Eu}^{3+}$ and ${ }^{4} \mathrm{~F}_{9 / 2} \rightarrow{ }^{6} \mathrm{H}_{\mathrm{J}}$ transitions, $J=15 / 2-11 / 2$ for $\mathrm{Dy}^{3+}$ upon UV excitation, in addition to the niobate emission. Representative results for these emission spectra are illustrated in Fig. 2 with the respective transition assignments. Samples of BLA: $\mathrm{Ln}^{3+}$ and BLACN: $\mathrm{Ln}^{3+}$ glasses were also investigated for comparison. The emission spectra of the $\mathrm{Ln}^{3+}$ ions are essentially identical in BLA, BLACN and BLANB glasses.

The excitation spectra of the $\mathrm{Eu}^{3+}$ emission in BLACN and 25BLANB10 glasses are shown in Fig. 3, and consist of several $\mathrm{f}-\mathrm{f}$ lines and a broad band in the UV region. The spectral resolution of these spectra and those of Fig. 4 was limited by the nature of the samples (glasses), since the inhomogeneous broadening is very large for transitions of optically active ions, such as $\mathrm{Eu}^{3+}$ and $\mathrm{Dy}^{3+}$, in glasses. For $\mathrm{Eu}^{3+}$ in BLA and BLACN glasses, Fig. 3a, the observed broad band is ascribed to a charge-transfer transition, which has been shown to play the role of a quenching state [10]. For $\mathrm{Eu}^{3+}$ in BLANB glasses, Fig. 3b, however, the broad band cannot be assigned only to the chargetransfer transition of $\mathrm{Eu}^{3+}$. A comparison with the excitation spectrum of the niobate emission in

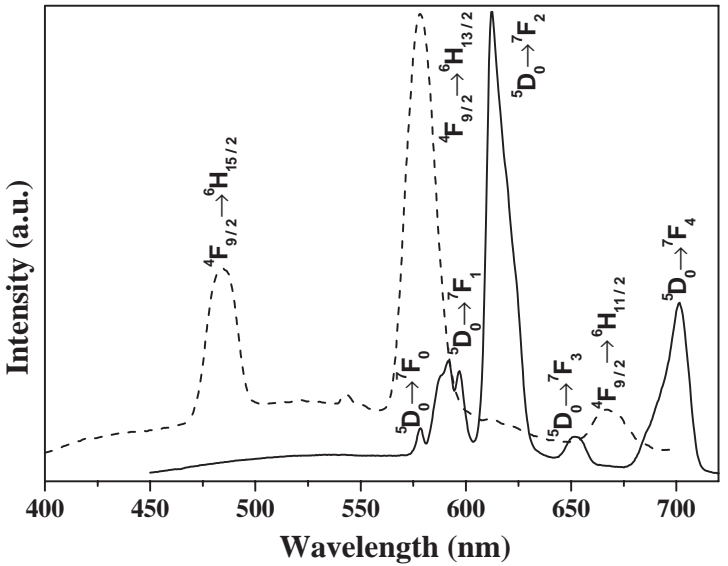

Fig. 2. Luminescence spectra at $4.2 \mathrm{~K}$ of $\mathrm{Eu}^{3+}$ in $24 \mathrm{La}_{2} \mathrm{O}_{3-}$ $18 \mathrm{Nb}_{2} \mathrm{O}_{5}-57 \mathrm{~B}_{2} \mathrm{O}_{3}: 1 \mathrm{Eu}_{2} \mathrm{O}_{3}$ (solid line) and of $\mathrm{Dy}^{3+}$ in $19 \mathrm{La}_{2} \mathrm{O}_{3}-$ $20 \mathrm{Nb}_{2} \mathrm{O}_{5}-60 \mathrm{~B}_{2} \mathrm{O}_{3}: 1 \mathrm{Dy}_{2} \mathrm{O}_{3}$ (dashed line) upon excitation at $290 \mathrm{~nm}$.

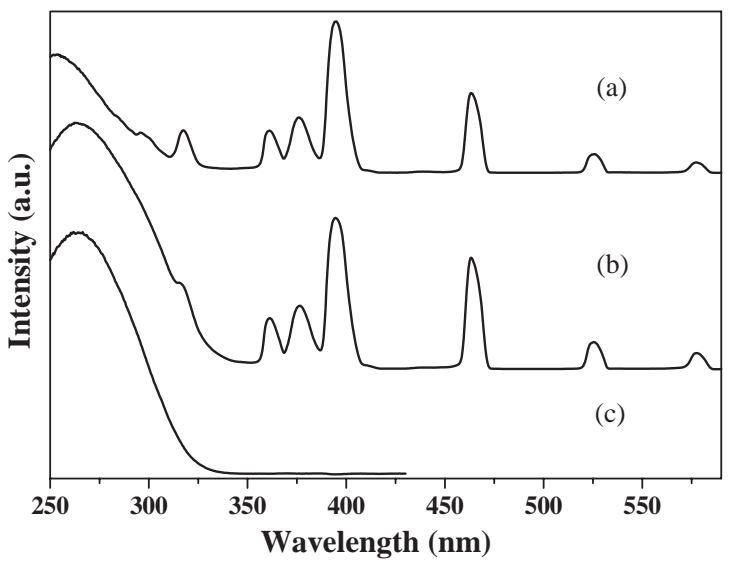

Fig. 3. Excitation spectra at $4.2 \mathrm{~K}$ of the: (a) ${ }^{5} \mathrm{D}_{0}$ emission $\left(\lambda_{\mathrm{em}}=615 \mathrm{~nm}\right) \quad$ of $\quad \mathrm{Eu}^{3+}$ in $4 \mathrm{CaO}-2 \mathrm{Na}_{2} \mathrm{O}-18 \mathrm{La}_{2} \mathrm{O}_{3}-$ $75 \mathrm{~B}_{2} \mathrm{O}_{3}: 1 \mathrm{Eu}_{2} \mathrm{O}_{3}$ glass; (b) ${ }^{5} \mathrm{D}_{0}$ emission $\left(\lambda_{\mathrm{em}}=615 \mathrm{~nm}\right)$ of $\mathrm{Eu}^{3+}$ in $24 \mathrm{La}_{2} \mathrm{O}_{3}-10 \mathrm{Nb}_{2} \mathrm{O}_{5}-65 \mathrm{~B}_{2} \mathrm{O}_{3}: 1 \mathrm{Eu}_{2} \mathrm{O}_{3}$ glass; and (c) niobate emission $\left(\lambda_{\mathrm{em}}=500 \mathrm{~nm}\right)$ in $24 \mathrm{La}_{2} \mathrm{O}_{3}-10 \mathrm{Nb}_{2} \mathrm{O}_{5^{-}}$ $65 \mathrm{~B}_{2} \mathrm{O}_{3}: 1 \mathrm{Eu}_{2} \mathrm{O}_{3}$ glass.

the same glass sample, Fig. $3 \mathrm{c}$, shows that the broad band observed in the excitation spectrum of the $\mathrm{Eu}^{3+}$ emission in 25BLANB10 glass closely resembles the excitation band of the niobate groups. This clearly indicates that there is energy transfer between the niobate groups and the $\mathrm{Eu}^{3+}$ ions in BLANB glasses, although the process does 


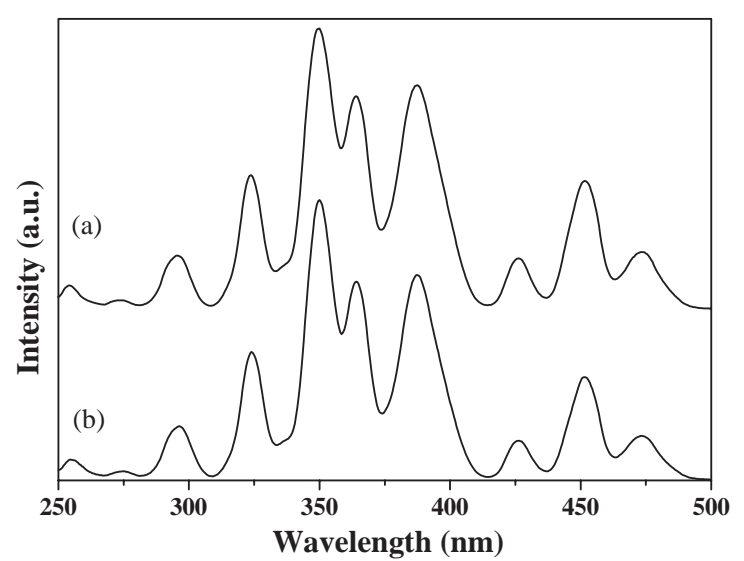

Fig. 4. Excitation spectra at $4.2 \mathrm{~K}$ of the ${ }^{4} \mathrm{~F}_{9 / 2}$ emission $\left(\lambda_{\mathrm{em}}=570 \mathrm{~nm}\right)$ of $\mathrm{Dy}^{3+}$ in (a) $19 \mathrm{La}_{2} \mathrm{O}_{3}-20 \mathrm{Nb}_{2} \mathrm{O}_{5}-60 \mathrm{~B}_{2} \mathrm{O}_{3}$ : $1 \mathrm{Dy}_{2} \mathrm{O}_{3}$ and (b) $4 \mathrm{CaO}-2 \mathrm{Na}_{2} \mathrm{O}-18 \mathrm{La}_{2} \mathrm{O}_{3}-75 \mathrm{~B}_{2} \mathrm{O}_{3}: 1 \mathrm{Dy}_{2} \mathrm{O}_{3}$ glasses.

not seem to be very efficient, since the band is only slightly more intense than the $\mathrm{f}-\mathrm{f}$ lines.

In contrast, the excitation spectra of the $\mathrm{Dy}^{3+}$ emission, presented in Fig. 4, consist of only $4 \mathrm{f}$ lines, and are identical in BLACN and BLANB glasses. It should also be noted that the excitation spectrum of the niobate emission in $19 \mathrm{La}_{2} \mathrm{O}_{3}$ $20 \mathrm{Nb}_{2} \mathrm{O}_{5}-60 \mathrm{~B}_{2} \mathrm{O}_{3}: 1 \mathrm{Dy}_{2} \mathrm{O}_{3}$ glass is, as expected, identical to that of Fig. $3 \mathrm{c}\left(24 \mathrm{La}_{2} \mathrm{O}_{3}-10 \mathrm{Nb}_{2} \mathrm{O}_{5}\right.$ $65 \mathrm{~B}_{2} \mathrm{O}_{3}: 1 \mathrm{Eu}_{2} \mathrm{O}_{3}$ glass). These results rule out the possibility of energy transfer from the niobate groups to the $\mathrm{Dy}^{3+}$ ion.

The differences in the behavior of the $\mathrm{Eu}^{3+}$ and $\mathrm{Dy}^{3+}$ ions can be assigned to the presence of a charge-transfer state for the $\mathrm{Eu}^{3+}$ in this region of the spectrum. Assuming that the energy transfer from the niobate excited states to the $\mathrm{Ln}^{3+}$ ions occurred by electric dipole interaction, it would be active over much longer distances (up to ca. $3 \mathrm{~nm}$ ) for the $\mathrm{Eu}^{3+}$ ion if charge-transfer states were involved [5]. In contrast, if the accepting states were $4 \mathrm{f}$ states, then the energy transfer would be active only up to ca. $0.5-0.7 \mathrm{~nm}$ [5].

The room temperature decay times for the emissions of the excited $\mathrm{Eu}^{3+}\left({ }^{5} \mathrm{D}_{0}\right)$ and $\mathrm{Dy}^{3+}$ $\left({ }^{4} \mathrm{~F}_{9 / 2}\right)$ ions in some selected glass samples are presented in Table 2. For the $\mathrm{Eu}^{3+}$ emission in BLANB glasses the decay times are independent of the lanthanide concentration (up to $3 \mathrm{~mol} \%$ ). This
Table 2

Decay times for the $\mathrm{Eu}^{3+}\left({ }^{5} \mathrm{D}_{0}\right)$ and $\mathrm{Dy}^{3+}\left({ }^{4} \mathrm{~F}_{9 / 2}\right)$ emissions at room temperature

\begin{tabular}{ll}
\hline Sample & Decay time $(\mathrm{ms})$ \\
\hline 25BLANB1:0.1-3Eu & 1.20 \\
25BLACN:0.1Eu & 1.50 \\
25BLANB:0.1Dy & 0.42 \\
19BLANB:0.5Dy & 0.33 \\
25BLANB:5Dy & 0.10 \\
25BLACN:0.1Dy & 0.69 \\
\hline
\end{tabular}

implies that inter-Eu ${ }^{3+}$ energy transfer processes are negligible in the samples investigated, as expected due to the low concentrations and the energy mismatch imposed by the glass disorder [5].

In contrast, the decay times for the emission of the $\mathrm{Dy}^{3+}$ ion in BLANB glasses are strongly dependent upon the lanthanide concentration, decreasing as the concentration increases. This effect is ascribed to cross-relaxation between $\mathrm{Dy}^{3+}$ pairs, for instance, the $\left({ }^{6} \mathrm{H}_{15 / 2},{ }^{4} \mathrm{~F}_{9 / 2}\right) \rightarrow\left({ }^{6} \mathrm{H}_{9 / 2}\right.$, ${ }^{6} \mathrm{~F}_{1 / 2}$ ) process [5] and is also observed for $\mathrm{Dy}^{3+}$ in BLACN glasses. These cross-relaxation processes are already noticed at rather low concentrations, for instance, 19BLANB:0.5Dy, suggesting that either the $\mathrm{Dy}^{3+}$ ions have a tendency to pair or there are $\mathrm{Ln}^{3+}$-rich domains in these glasses.

The decay times of $\mathrm{Eu}^{3+}$ and $\mathrm{Dy}^{3+}$ in BLACN glasses are longer than those observed in BLANB glasses, indicating that the niobate groups increased the covalent contribution to the ligandfield at the $\mathrm{Ln}^{3+}$ sites. This can be ascribed to larger average oxygen polarizabilities, consistent with the higher refractive indices of BLANB glasses in comparison with BLA and BLACN glasses [4].

We have reported before [4] that the introduction of $\mathrm{Bi}^{3+}$ in 19BLANB20 glasses gives rise to a broad band emission $\left(\lambda_{\mathrm{em} \text { (max }}=570 \mathrm{~nm}\right.$, $\left.\lambda_{\operatorname{exc}(\max )}=340 \mathrm{~nm}\right)$. Based on the strong temperature dependence of the decay times [4] and on the absence of such an emission in BLACN: $\mathrm{Bi}^{3+}$ glasses, this band was tentatively assigned to the so-called "D-level", that is, a $\mathrm{Bi}^{3+} \rightarrow \mathrm{Nb}(\mathrm{V})$ charge-transfer state $[4,5]$. However, this assignment is not consistent with the emission of $\mathrm{Bi}^{3+}$ in $\mathrm{LaNbO}_{4}\left(\lambda_{\mathrm{em}(\max )}=450 \mathrm{~nm}\right)$, although an 


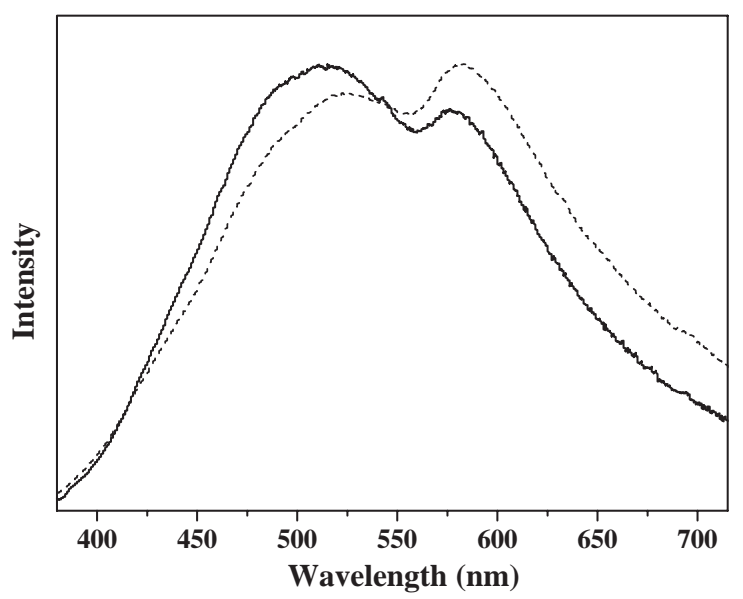

Fig. 5. Emission spectra at $4.2 \mathrm{~K}$ of BLANB10: $\mathrm{Bi}^{3+}$ upon excitation at $300 \mathrm{~nm}$ (dashed line) and $260 \mathrm{~nm}$ (solid line).

absorption maximum at $340 \mathrm{~nm}$ is in fact observed and ascribed to $\mathrm{Bi}-\mathrm{O}$ groups [11]. Therefore, in order to achieve a better understanding of the $\mathrm{Bi}^{3+}$ emission in BLANB glasses we have investigated samples with lower $\mathrm{Nb}(\mathrm{V})$ concentrations.

The emission spectra of BLANB10: $\mathrm{Bi}^{3+}$ and BLANB18: $\mathrm{Bi}^{3+}$ upon UV excitation are presented in Fig. 5. They are very similar and can be described as two overlapping broad bands with maxima at 520 and $580 \mathrm{~nm}$, with maxima at $580 \mathrm{~nm}$ being more intense for the BLANB18: $\mathrm{Bi}^{3+}$ sample.

The excitation spectra of BLANB10: $\mathrm{Bi}^{3+}$ and BLANB18: $\mathrm{Bi}^{3+}$ for the emissions at $520 \mathrm{~nm}$ are presented in Fig. 6. They can be characterized as two overlapping bands with maxima at 270 and $300 \mathrm{~nm}$ for BLANB10: $\mathrm{Bi}^{3+}$ and an even broader band for BLANB18: $\mathrm{Bi}^{3+}$, with an intense tail extending up to $360 \mathrm{~nm}$.

Excitation at wavelengths longer than $300 \mathrm{~nm}$ enhances the $580 \mathrm{~nm}$ emission band, whereas excitation at wavelengths shorter than $270 \mathrm{~nm}$ enhances the $520 \mathrm{~nm}$ emission. The emission band at $300 \mathrm{~nm}$ for BLANB10: $\mathrm{Bi}^{3+}$ is similar to the excitation of $\mathrm{Bi}^{3+}$ observed [10] in BLACN glasses $\left(\lambda_{\mathrm{em}(\max )}=420 \mathrm{~nm}, \quad \lambda_{\mathrm{exc}(\max )}=300 \mathrm{~nm}\right) . \quad$ Both bands in the excitation spectra presented a strong temperature dependence, namely, they decreased by a factor 40 for BLANB10:Bi ${ }^{3+}$ and 100 for BLANB18: $\mathrm{Bi}^{3+}$ when the temperature increased

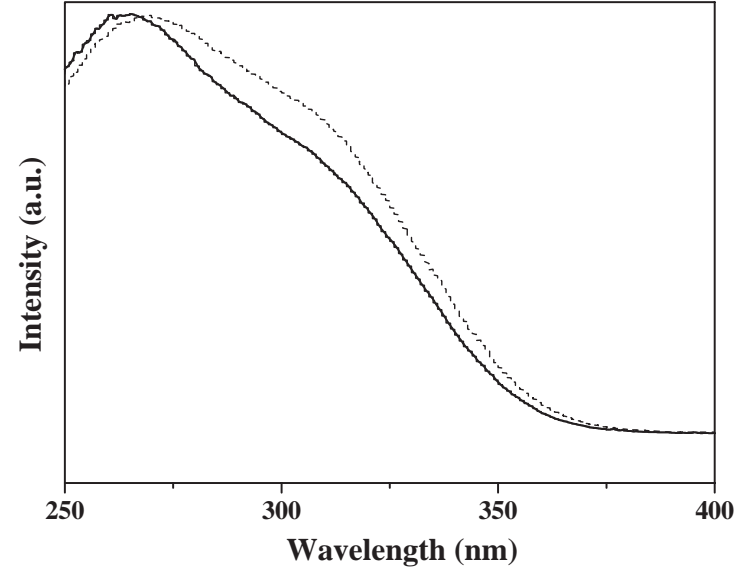

Fig. 6. Excitation spectra at $4.2 \mathrm{~K}$ of BLANB18: $\mathrm{Bi}^{3+}$ (dashed line) and $\mathrm{BLANB} 10: \mathrm{Bi}^{3+}$ (solid line) at $520 \mathrm{~nm}$.

from 4.2 to $300 \mathrm{~K}$. It is important to notice that both emission bands were already observed in the undoped samples (Fig. 1), although the $520 \mathrm{~nm}$ was clearly dominant. Furthermore, only the excitation band at $270 \mathrm{~nm}$ can be distinguished in the undoped sample (Fig. 1). These results showed that the $\mathrm{Bi}^{3+}$ ions transfer their excitation energy preferentially to extrinsic niobate groups, thus suggesting that the $\mathrm{Bi}^{3+}$ ions favor sites closer to extrinsic niobate groups, that is, niobates lacking oxygen. It is known that ions with $6 s^{2}$ configuration, such as $\mathrm{Bi}^{3+}$, favor asymmetrical sites and tend to strengthen the asymmetry (pseudo-JahnTeller effect) [5]. At higher $\mathrm{Nb}(\mathrm{V})$ concentrations (ca. $20 \mathrm{~mol} \% \quad \mathrm{Nb}_{2} \mathrm{O}_{5}$ ) the interaction between the $\mathrm{Bi}^{3+}$ ions and the extrinsic niobate groups becomes stronger, favoring the formation of a $\mathrm{Bi}^{3+} \rightarrow$ extrinsic niobate charge-transfer state (band at $340 \mathrm{~nm}$ ).

\section{Conclusion}

The $\mathrm{Nb}(\mathrm{V})$ ions are incorporated into the glass network as $\mathrm{NbO}_{6}$ octahedra, substituting $\mathrm{BO}_{4}$ groups and giving rise to non-bridging oxygens. As the $\mathrm{Nb}(\mathrm{V})$ concentration increases, the $\mathrm{NbO}_{6}$ groups condense into a subnetwork by edgesharing and later by corner sharing, giving rise to energy migration and luminescence quenching. 
Energy transfer from the niobate groups to the lanthanide ions was observed for $\mathrm{Eu}^{3+}$, probably due to the presence of charge-transfer states, but not for $\mathrm{Dy}^{3+}$, which has no charge-transfer state in the investigated spectral region. The existence of energy transfer between the $\mathrm{Ln}^{3+}$ ions can be ruled out for $\mathrm{Eu}^{3+}$ up to concentrations of $3 \mathrm{~mol} \%$, but is very important for $\mathrm{Dy}^{3+}$, due to the cross-relaxation processes. The niobate groups increased the covalent contribution to the ligandfield at the $\mathrm{Ln}^{3+}$ sites, probably due to the enhancement of the average oxygen polarizability. The $\mathrm{Bi}^{3+}$ ions in BLANB glasses transfer their excitation energy preferentially to oxygen deficient (extrinsic) niobate groups.

\section{Acknowledgements}

Partial financial support from the Brazilian agencies CNPq and PADCT is gratefully acknowledged. One of the authors (WDF) wishes to acknowledge $\mathrm{CNPq}$ for providing a graduate scholarship. We are indebted to Prof. A. Meijerink (Universiteit Utrecht, The Netherlands) for in- sightful discussions and for kindly allowing the use of his laboratory facilities.

\section{References}

[1] T. Cardinal, E. Fargin, G. Le Flem, M. Couzi, L. Canioni, P. Segonds, L. Sarger, A. Ducasse, F. Adamietz, Eur. J. Solid State Inorg. Chem. 33 (1996) 597.

[2] E.M. Vogel, S.G. Kosinski, D.M. Krol, J.L. Jackel, S.R. Friberg, M.K. Oliver, J.D. Powers, J. Non-Cryst. Solids 107 (1989) 244.

[3] B. Samuneva, St. Kralchev, V. Dimitrov, J. Non-Cryst. Solids 129 (1991) 54.

[4] A.C.V. de Araújo, I.T. Weber, W.D. Fragoso, C. de Mello Donegá, J. Alloys Compounds 275-277 (1998) 738.

[5] G. Blasse, B.C. Grabmaier, Luminescent Materials, Springer, Berlin, 1994.

[6] G. Blasse, J. Solid State Chem. 72 (1988) 72.

[7] M.F. Hazenkamp, AW.P.M. Strijbosch, G. Blasse, J. Solid State Chem. 97 (1992) 115.

[8] G. Blasse, G.J. Dirksen, Inorg. Chim. Acta 157 (1989) 141.

[9] H.C.G. Verhaar, H. Donker, G.J. Dirksen, M.J.J. Lammers, G. Blasse, C.C. Torardi, L.H. Brixner, J. Solid State Chem. 60 (1985) 20.

[10] J.W.M. Verwey, G. Blasse, Mat. Chem. Phys. 25 (1990) 91.

[11] D.A. Grisafe, C.W. Fritsch Jr., J. Solid State Chem. 17 (1976) 313. 